\title{
Pregnancy in multiple sclerosis: from scientific aspects to practical
}

\author{
${ }^{\star 1}$ Anna Belenciuc, ${ }^{1,2}$ Ana-Maria Bubuioc, ${ }^{1}$ Olesea Odainic, ${ }^{1,2}$ Marina Sangheli, \\ ${ }^{1,2}$ Mihail Gavriliuc, ${ }^{1,2}$ Vitalie Lisnic \\ ${ }^{1}$ Diomid Gherman Institute of Neurology and Neurosurgery \\ ${ }^{2}$ Department of Neurology No 1, Nicolae Testemitanu State University of Medicine and Pharmacy \\ Chisinau, the Republic of Moldova
}

\author{
Authors' ORCID iDs, academic degrees and contribution are available at the end of the article \\ *Corresponding author - Anna Belenciuc, e-mail: belenciuc@gmail.com \\ Manuscript received July 12, 2021; revised manuscript August 18, 2021; published online September 10, 2021
}

\begin{abstract}
Background: Multiple sclerosis (MS) is a disease that affects young people of reproductive age (20-40 years old), predominantly women. Therefore, almost every patient has questions about pregnancy and breastfeeding. Family planning is one of the key issues in the choice of treatment tactics. Despite the growing number of therapeutic options for individualized treatment, it is still a question how to manage women with MS who become pregnant while taking disease-modifying drugs or want to become pregnant after starting this treatment.

Conclusions: Women with MS should not be discouraged from pregnancy due to their illness. It is necessary to proactively discuss pregnancy planning with all women with MS of childbearing age. Based on available data, interferon beta and glatiramer acetate appear to be most suitable for use up until the time of confirmed pregnancy. A large amount of data (more than 1000 cases) obtained from registries shows that use of interferon beta before conception and during pregnancy suggests no evidence of increase in the rate of congenital anomalies or spontaneous abortions. For women with persistent high disease activity, pulsed immune reconstitution therapy gives additional opportunity for family planning after the last dose. The choice between available options for pulsed immune reconstitution therapy should be based on efficacy balanced against the risks.

Key words: multiple sclerosis, pregnancy, disease-modifying treatment.
\end{abstract}

Cite this article

Belenciuc A, Bubuioc A-M, Odainic O, Sangheli M, Gavriliuc M, Lisnic V. Pregnancy in multiple sclerosis: from scientific aspects to practical. Mold Med J. 2021;64(3):78-84. https://doi.org/10.52418/moldovan-med-j.64-3.21.14.

\section{Introduction}

Multiple sclerosis (MS) is most often diagnosed between the ages of 20-40, the age at which many people may be thinking of starting or extending their family. Recent analysis of the 3rd edition of the Atlas of MS as an open-source global compendium of data regarding the epidemiology of MS showed that globally females are twice as likely to have MS as males and this is consistent with both prior editions of the Atlas. However, the ratio of women to men is as high as 4:1 in some countries, and in others this ratio has doubled since 2013 [1]. This disproportional increase of MS incidence in females, particularly notable in the Middle East, is explained by some investigators as a result of improved diagnostic methods and a better access to MRI $[2,3]$.

In a survey of 5949 patients, registered in the NARCOMS (North American Research Committee on Multiple Sclerosis) database, $79 \%$ of patients did not become pregnant after a diagnosis of MS. In $34.5 \%$ of these patients, the choice concerned MS-related issues [4]. A survey on 271 female patients with MS in Switzerland undertaken to help understand the effects of family planning on their treatment decisions revealed their concerns about: disease course dur- ing pregnancy (44\%), disease course after pregnancy (61\%), the health of the unborn child (47\%), possibility for breastfeeding (21\%), taking care of the child after birth (45\%), the availability of MS therapy options (35\%) [5]. It is important to provide a framework to discuss concerns regarding pregnancy and MS, as well as the uncertainty about the course of disease during pregnancy, postpartum and in the long-term.

Management of women with MS is a complex task that should cover pre-pregnancy guidance, care during pregnancy, delivery and anesthetic options, postpartum and specific advice concerning currently approved disease-modifying drugs [6].

Despite the growing number of therapeutic options for individualized treatment, it is still a question how to manage MS in women who become pregnant while taking diseasemodifying drugs or want to become pregnant after starting this treatment. It is therefore important to proactively discuss family planning and pregnancy, especially when considering disease-modifying treatments. As the complexity and spectrum of available disease-modifying drugs increase, in many countries MS pregnancy data is being gathered in nationwide registries. 
This literature review that includes data from national registries demonstrates the modern approach to the management of women with MS with reproductive potential depending on the disease activity and the stage of family planning.

\section{Discussion}

Today it is known that MS is not a hereditary disease, and does not significantly affect the ability of conception, and the likelihood of adverse pregnancy outcomes such as the risk of spontaneous abortions, stillbirth, cesarean delivery, premature birth, or birth defects [4]. However, pregnancy planning should not coincide with time of diagnosis, to allow for evaluation of disease activity and course. It is recommended to ensure disease control before pregnancy, depending on disease activity with stabilization for at least 1 year before pregnancy. Proactive counselling and formulation of a pregnancy and disease management plan with at least annual revision may help to avoid the situation when following discussion with their health care practitioner (HCP), women with MS defer treatment because they wish to have children in the future [6-8].

Women with MS should follow standard advice for all pregnant women: ensure good sleep, hygiene, and diet, avoid alcohol and smoking, take recommended routine prenatal supplements including folic acid $[4,6,7]$. Along with the absence of a significant impact of MS on child health, women with MS considering pregnancy should be counseled upon the unpredictable course of MS, the effect of MS on the course of pregnancy, on how the pregnancy may affect disease. The potential teratogenic risk associated with disease modifying drugs (DMDs) and the increased risk of vitamin D deficiency associated with MS should also be discussed within pre-pregnancy consultation $[6,9,10]$.

Although MS has no significant impact on the ability of women to conceive, about $10 \%$ of all women have difficulties getting or staying pregnant and may choose to use assisted reproductive technology (ART) [4]. In most studies, women stopped taking DMDs prior to initiating ART, leaving them at a higher risk of relapse. Additionally patients with MS may experience an increase in relapse rate following the use of ART, which may be the result of stress and hormone alterations associated with ART. Distress is also associated with in-vitro fertilization failure $[7,11]$.

While women are pregnant, they may experience fewer MS relapses, especially in the third trimester [12-14]. However, in patients with highly active disease, pregnancy may not be sufficient to control disease activity [6]. About 25\% of women experience a relapse within 40 weeks of pregnancy and nearly $30 \%$ within the first 3 months after giving birth. These data are mainly derived from studies involving untreated women during and after pregnancy. A risk factor for increased disease activity after childbirth is relapse during the year before and during pregnancy [15]. It is important to note that pregnancy has no effect on the progression of disability in MS [16]. In this regard, it is important to continue therapy, but most DMDs are contraindicated during pregnancy (tab. 1).
Pregnancy may often complicate the diagnosis of new disease activity. Clinical presentation of MS can be similar to common pregnancy-related symptoms, which makes it difficult to attribute any symptoms to the disease process if they develop during an established pregnancy [17]. Although pregnant women may experience fewer relapses, pregnancy may exacerbate other MS symptoms. One of the most common pregnancy-related symptoms similar to presentation of MS is fatigue. Pregnant women may find that they do not sleep well, and maternal iron deficiency may also lead to anaemia and fatigue. Current evidence suggests that women with MS have a higher risk of anaemia during pregnancy when compared with healthy individuals [17]. In some countries (in the U.S.) amantadine is used as the only approved treatment for fatigue, but there are no adequate studies in pregnant women regarding the use of this medication. In pregnancy, increasing weight may diminish mobility which can mimic reduced mobility in MS. Spasticity and gait abnormalities may worsen with pregnancy. Pressure from the uterus on the bladder may increase frequency of urination resembling bladder and bowel dysfunction. Vision changes due to pregnancy-induced hypertension as well may seem to the patient as a manifestation of MS, therefore other possible causes of vision problems should also be excluded.

Indicators of new onset of MS symptoms may include sensory changes, paralysis, muscle weakness or spasm, cognitive changes. Pregnant women with MS who notice worsening of pre-existing conditions or a new onset of distinct MS-related symptoms should undergo neurological examination. The neurological condition of all pregnant patients with MS should be ideally checked every 3 months including screening for depression and anxiety given that many women with MS may experience a higher incidence of depression during pregnancy [17]. Existing comorbidities can also contribute to general deterioration. Urinary tract infections may be more frequent in pregnant women with MS when compared with pregnant healthy controls $[6,17]$. To date there is a current lack of data on the safety of treatments for some comorbidities in pregnant women. Regarding treatment of severe relapses during pregnancy warranting treatment published literature reports on corticosteroids, which may be considered depending on corticosteroid type, period of pregnancy, and duration of treatment and dosage. During the second and third trimesters, short courses (3-5 days) of prednisolone or methylprednisolone may be considered. Corticosteroid administration should be avoided during the first trimester of pregnancy due to the potential, but rare, risk of teratogenic effects (e.g. cleft palate). Plasma exchange may be taken into account for severe relapses that are not responsive to corticosteroid treatment $[6,7,18]$.

For women who experience relapse warranting imaging, there are no conclusive data to show that MRI exposure up to $3 \mathrm{~T}$ is associated with foetal harm, but gadolinium should be avoided $[6,7,18]$. Regarding additional foetal scans in women with MS, Association of British Neurologists (ABN) guidelines state that it is not required [6].

Today it is known that after childbirth, the level of hor- 
mones and cytokines returns to normal and the activity of the disease increases. This gradual normalization decreases the immunosuppressive effect of pregnancy and leads to an increase in MS activity. Additionally, this can also be facilitated by the stressful effect of childbirth itself and the increasing stress in a woman associated with childcare.

Global trends show that the waiting time before resuming therapy after childbirth can last up to 100 days, which is often associated with the inability to use DMD during breastfeeding, although therapy is extremely important to reduce disease activity and slow the progression of disability. According to Hellwig K. et al., 2012 about $30 \%$ of women experience a relapse within the first 3 months after giving birth. This data was obtained from patients who were not taking DMDs [15].

Some of the implications of stopping DMDs use which must be considered are: loss of disease-control benefits after stopping DMDs requiring continuous administration, potential rebound disease, further monitoring, and elimination periods of up to 48 months for some medications. Recommended preconception washout periods for DMDs vary greatly (tab. 1).

International American Academy of Neurology (AAN) 2018 and ABN 2019 guidelines state that DMD choice may be influenced by plans for pregnancy and during prepregnancy counselling, HCPs should consider the safety of all drug treatments during pregnancy when prescribing to women of childbearing age $[6,32]$.

According to ECTRIMS/EAN 2018 guidelines the use of interferon beta or glatiramer acetate until pregnancy is confirmed may be considered for women with a high risk of disease re-activation; treatment continuation may be considered in specific cases. In women with persistent high disease activity who do not wish to delay pregnancy, treatment with some DMDs during pregnancy could be an option after discussion of the potential implications [33].

Based on available data, interferon beta and glatiramer acetate appear to be most suitable for use up until the time of confirmed pregnancy. However, a systematic review concluded that further research was necessary for glatiramer acetate as studies were small. Natalizumab is a large molecule that is unlikely to cross the placental barrier to any great extent during early pregnancy. If natalizumab is administered in the last quarter of pregnancy, concentrations may be higher in infants than in mothers which can result in reversible hematological abnormalities such as thrombocytopenia and anemia. Natalizumab must be discontinued at a maximum of 3 months prior to pregnancy. After consideration of the individual risk-benefit, natalizumab may be given until pregnancy is confirmed or, in rare cases, the benefit of continuing natalizumab during the entire pregnancy may outweigh the risk of recurring severe disease activity but only after careful risk-benefit consideration. It is recommended that a pediatrician be in attendance during delivery and that blood cell count, liver enzymes, haptoglobin and bilirubin be controlled in the newborn [16].

To date, emerging data continue to change family plan- ning for people with MS given the increased identification of long-term developmental effects on children exposed to DMDs.

Data from global registries demonstrates that there is no evidence of an adverse effect of interferon beta-1a on pregnancy outcomes or on the frequency of live births of children with congenital abnormalities. Both indicators, as well as the body weight of newborns, are in accordance with indicators in the general population. Based on over 1000 pregnancy outcomes, obtained from registers and post-registration observations, EMA approved respective changes in label.

The European Interferon-beta Pregnancy Registry is a prospective collection of pregnancy data from interferon beta-treated women from 31 European countries. Between 2009 and 2017, the registry collected 948 pregnancy reports with a known pregnancy outcome. This is one of the largest prospective cohort studies conducted to date, providing data on pregnancy outcomes in women with MS who received interferon beta. Of the known outcomes, 794 were live births. Overall, 82.0\% (777/948) of pregnancies resulted in live birth without congenital anomaly. When comparing IFN-beta-exposed pregnancies with the general population, the prevalence of spontaneous abortions (10.7\% vs $10-21 \%)$ and congenital anomalies in live births (2.1\% vs $2.1-4.1 \%)$ were found to be within reported ranges. The data gathered from these pregnancy cases suggest no evidence that IFNbeta exposure before conception and/or during pregnancy adversely increases the rate of congenital anomalies or spontaneous abortions [34].

The German MS Pregnancy Registry is a nationwide collection of data on pregnancy outcomes for women diagnosed with relapsing-remitting MS, conducted from 2008 to 2013. It was shown that the proportion of live births, average body weight and length at birth, as well as the time of onset of labor in patients with MS who took interferon beta $(n=251)$ were comparable to those in the group untreated with DMDs ( $\mathrm{n}=194)$ [35].

The Scandinavian registry includes data on pregnancies in Finland and Sweden from 1996 to 2014 ( $\mathrm{n}=3054)$. According to its results, there was no evidence of adverse pregnancy outcomes in connection with the use of interferon beta. The incidence of spontaneous abortions is comparable in the interferon beta-1a cohort and in the cohort without DMD treatment (8.1\% vs $11.1 \%$ respectively). The proportion of cases of ectopic pregnancy in women who received interferon beta-1a was $1.6 \%$ vs $2.9 \%$ in the group without DMD treatment. The weight of the live births without congenital abnormalities in the groups receiving and not receiving therapy was similar [36].

The database analysis by Sandberg-Wollheim M. et al., 2011 presents prospective and retrospective reports on the safety of Rebif (interferon beta 1-a), including post-market observational data and isolated reports from clinical trials. Prospective data $(n=425)$ indicate no increase in the incidence of spontaneous abortions in women who received Rebif $(11.5 \%)$ compared to the general population (up to 20\%) [37]. 
Table 1. Recommended contraception period (months after last dose) use during pregnancy and breastfeeding according to EU Summary of Product Characteristics (SmPC) of DMD

\begin{tabular}{|c|c|c|c|}
\hline DMD & $\begin{array}{l}\text { Contraception requirements/ } \\
\text { washout period }\end{array}$ & Use during pregnancy/reproductive toxicity data & Use during breastfeeding \\
\hline $\begin{array}{l}\text { Alemtuzumab } \\
\text { [19] }\end{array}$ & $\begin{array}{l}\text { Contraception use recom- } \\
\text { mended for } 4 \text { months follow- } \\
\text { ing each course of treatment }\end{array}$ & $\begin{array}{l}\text { Alemtuzumab may cross the placental barrier and thus } \\
\text { be potentially dangerous to the fetus. Animal studies } \\
\text { have demonstrated reproductive toxicity. It is not known } \\
\text { whether alemtuzumab can harm the fetus when given } \\
\text { to pregnant women or whether it can alter reproductive } \\
\text { capacity. Alemtuzumab should be administered during } \\
\text { pregnancy only if the potential benefit justifies the po- } \\
\text { tential risk to the fetus. }\end{array}$ & $\begin{array}{l}\text { Breast-feeding should be sus- } \\
\text { pended during each course of } \\
\text { treatment and for } 4 \text { months fol- } \\
\text { lowing the last infusion of each } \\
\text { treatment course. }\end{array}$ \\
\hline $\begin{array}{l}\text { Cladribine } \\
\text { tablets [20] }\end{array}$ & $\begin{array}{l}\text { Contraception use recom- } \\
\text { mended for } 6 \text { months after last } \\
\text { dose, ensuring that a barrier } \\
\text { method is included during } \\
\text { treatment and } 1 \text { month after } \\
\text { last dose }\end{array}$ & $\begin{array}{l}\text { Animal studies have shown reproductive toxicity. Cladrib- } \\
\text { ine is contraindicated in pregnant women }\end{array}$ & $\begin{array}{l}\text { Breast-feeding should be discon- } \\
\text { tinued during treatment with } \\
\text { cladribine and for } 1 \text { week after } \\
\text { the last dose }\end{array}$ \\
\hline $\begin{array}{l}\text { Dimethyl fuma- } \\
\text { rate [21] }\end{array}$ & None given & $\begin{array}{l}\text { Animal studies have shown reproductive toxicity. Di- } \\
\text { methyl fumarate is not recommended during pregnancy } \\
\text { and in women of childbearing potential not using ap- } \\
\text { propriate contraception }\end{array}$ & $\begin{array}{l}\text { A decision must be made wheth- } \\
\text { er to discontinue breast-feeding } \\
\text { or to discontinue dimethyl } \\
\text { fumarate therapy }\end{array}$ \\
\hline $\begin{array}{l}\text { Glatiramer } \\
\text { acetate [22] }\end{array}$ & None given & $\begin{array}{l}\text { Studies in animals have not shown reproductive toxicity. } \\
\text { Current data on the use of glatiramer acetate } 20-40 \mathrm{mg} / \\
\mathrm{ml} \text { in pregnant women indicate no malformative or feto/ } \\
\text { neonatal toxicity. To date, no relevant epidemiologi- } \\
\text { cal data are available. As a precautionary measure, it is } \\
\text { preferable to avoid the use of glatiramer acetate during } \\
\text { pregnancy unless the benefit to the mother outweighs } \\
\text { the risk to the foetus. }\end{array}$ & $\begin{array}{l}\text { A decision must be made } \\
\text { whether to discontinue breast- } \\
\text { feeding or to discontinue/abstain } \\
\text { from glatiramer acetate therapy } \\
\text { taking into account the benefit } \\
\text { of breast-feeding for the child } \\
\text { and the benefit of therapy for the } \\
\text { woman. }\end{array}$ \\
\hline $\begin{array}{l}\text { Interferons } \\
{[24-26]}\end{array}$ & None given & $\begin{array}{l}\text { A considerable amount of data (more than } 1000 \text { preg- } \\
\text { nancy outcomes) from registries and post-marketing ex- } \\
\text { perience does not show a higher risk of major congenital } \\
\text { anomalies after exposure to interferon beta during pre- } \\
\text { conception or the first trimester of pregnancy. However, } \\
\text { the extent of exposure during the first trimester is ques- } \\
\text { tionable, given that data were gathered when interferon } \\
\text { beta use was contraindicated during pregnancy, and } \\
\text { treatment was presumably stopped when pregnancy } \\
\text { was detected and/or confirmed. Evidence regarding } \\
\text { exposure during the second and third trimester is very } \\
\text { limited. } \\
\text { Based on animal studies, there is a possibly higher risk for } \\
\text { spontaneous abortion. The risk of spontaneous abor- } \\
\text { tions in pregnant women exposed to interferon beta } \\
\text { cannot be appropriately evaluated based on the data } \\
\text { that are available, but the evidence does not suggest an } \\
\text { increased risk thus far. } \\
\text { If clinically needed, the use of interferon beta may be } \\
\text { considered during pregnancy. }\end{array}$ & $\begin{array}{l}\text { Limited information available on } \\
\text { the transfer of interferon beta-1a } \\
\text { into breast milk, together with } \\
\text { the chemical/physiological } \\
\text { characteristics of interferon beta, } \\
\text { suggests that levels of interferon } \\
\text { beta-1a excreted in human milk } \\
\text { are negligible. No harmful effects } \\
\text { on the breastfed newborn/infant } \\
\text { are anticipated. } \\
\text { Interferon beta can be used dur- } \\
\text { ing breast-feeding. }\end{array}$ \\
\hline
\end{tabular}




\begin{tabular}{|c|c|c|c|}
\hline $\begin{array}{l}\text { Mitoxantrone } \\
\text { [27] }\end{array}$ & $\begin{array}{l}\text { Contraception use recom- } \\
\text { mended for at least } 4 \text { months } \\
\text { for women and at least } \\
6 \text { months for men after last } \\
\text { dose }\end{array}$ & $\begin{array}{l}\text { There are very limited data on the use of mitoxantrone } \\
\text { in pregnant women. Mitoxantrone was not teratogenic } \\
\text { in animal studies at doses below human exposure but } \\
\text { caused reproductive toxicity. Mitoxantrone is considered } \\
\text { a potential human teratogen because of its mechanism } \\
\text { of action and the developmental effects demonstrated } \\
\text { by related agents. For this reason, the use of mitoxan- } \\
\text { trone to treat MS is contraindicated for pregnant women. }\end{array}$ & $\begin{array}{l}\text { Because of the potential for seri- } \\
\text { ous adverse reactions in infants } \\
\text { from mitoxantrone, breast-feed- } \\
\text { ing is contraindicated and must } \\
\text { be discontinued before starting } \\
\text { treatment. }\end{array}$ \\
\hline $\begin{array}{l}\text { Natalizumab } \\
\text { [28] }\end{array}$ & None given & $\begin{array}{l}\text { If a woman becomes pregnant while taking natalizumab, } \\
\text { discontinuation of treatment should be considered. A } \\
\text { benefit-risk evaluation of the use of natalizumab during } \\
\text { pregnancy should take into account the patient's clinical } \\
\text { condition and the possible return of disease activity after } \\
\text { stopping the treatment. } \\
\text { Animal studies have demonstrated reproductive toxicity. } \\
\text { Data from clinical trials, a prospective pregnancy registry, } \\
\text { post-marketing cases and available literature do not } \\
\text { suggest an effect of this medicinal product exposure on } \\
\text { pregnancy outcomes. } \\
\text { The completed prospective natalizumab pregnancy reg- } \\
\text { istry contained } 355 \text { cases and their outcomes. There were } \\
316 \text { live births, } 29 \text { of which were reported to have birth } \\
\text { defects. Sixteen of the } 29 \text { were considered major defects. } \\
\text { The rate of defects corresponds to the ones reported in } \\
\text { other pregnancy registries involving MS patients. There } \\
\text { is no evidence of a specific pattern of birth defects with } \\
\text { this drug. } \\
\text { Cases from published literature reported transient mild } \\
\text { to moderate thrombocytopenia and anaemia observed } \\
\text { in infants born to women exposed to natalizumab in } \\
\text { their third trimester of pregnancy. Therefore, it is recom- } \\
\text { mended that newborns of women exposed to this drug } \\
\text { during the third trimester of pregnancy are screened for } \\
\text { potential haematological complications. }\end{array}$ & $\begin{array}{l}\text { Breast-feeding should be discon- } \\
\text { tinued during treatment with } \\
\text { natalizumab. }\end{array}$ \\
\hline $\begin{array}{l}\text { Ocrelizumab } \\
\text { [29] }\end{array}$ & $\begin{array}{l}\text { Contraception use recom- } \\
\text { mended for } 12 \text { months after } \\
\text { last dose }\end{array}$ & $\begin{array}{l}\text { There is a limited amount of data from the use of ocreli- } \\
\text { zumab in pregnant women. Postponing vaccination with } \\
\text { live or live-attenuated vaccines should be considered for } \\
\text { neonates and infants born to mothers who have been } \\
\text { exposed to ocrelizumab in utero. No B cell count data } \\
\text { have been collected in neonates and infants exposed to } \\
\text { ocrelizumab and the potential duration of B-cell deple- } \\
\text { tion in neonates and infants is unknown. } \\
\text { Animal studies (embryo-fetal toxicity) do not indicate } \\
\text { teratogenic effects. B-cell depletion in utero was de- } \\
\text { tected. Reproductive toxicity was observed in pre- and } \\
\text { post-natal development studies. } \\
\text { Ocrelizumab should be avoided during pregnancy unless } \\
\text { the potential benefit to the mother outweighs the poten- } \\
\text { tial risk to the foetus. }\end{array}$ & $\begin{array}{l}\text { Women should be advised to } \\
\text { discontinue breast-feeding } \\
\text { during ocrelizumab therapy. }\end{array}$ \\
\hline $\begin{array}{l}\text { Teriflunomide } \\
{[30,31]}\end{array}$ & $\begin{array}{l}\text { Recommend accelerated elimi- } \\
\text { nation to achieve }<0.02 \mathrm{mg} / \mathrm{L} \\
\text { if pregnancy occurs/prior to } \\
\text { stopping contraceptive use }\end{array}$ & $\begin{array}{l}\text { Studies in animals have shown reproductive toxi-city. } \\
\text { Teriflunomide may cause serious birth defects when } \\
\text { administered during pregnancy. Teriflunomide is contra- } \\
\text { indicated in pregnancy. }\end{array}$ & $\begin{array}{l}\text { Teriflunomide is contraindicated } \\
\text { during breast-feeding }\end{array}$ \\
\hline
\end{tabular}

There is limited information on the penetration of interferon beta-1a into breast milk. It is known that interferon beta-1a is not able to easily get into breast milk, since it is a large polar molecule (22500 Da) closely bound up with Tlymphocytes and other immune cells. Newborns can receive
$0.0006 \%$ of the maternal dose of interferon beta-1a in breast milk. In addition, interferon beta-1a is poorly absorbed when taken orally, so it is not expected to get into the bloodstream of a newborn when breastfeeding [38, 39]. Latest EU label permit to take interferon beta-1a during breastfeeding 
period. Whereas in the case of glatiramer acetate preparations, a choice should be made between lactation and their intake, weighing the benefits for the child from breast feeding and the benefits of the mother from treatment.

There's a lack of treatment options for women with persistent high disease activity who do not wish to delay pregnancy. However, with the advent of pulsed immune reconstitution therapies represented with alemtuzumab and cladribine there's additional opportunity for family planning. Whereas drugs used for maintenance or escalation therapy do not maintain their beneficial effect after cessation of therapy, these new highly effective therapies can show prolonged treatment effects after a short treatment course [40]. Despite that mitoxantrone could be used not only as induction, but as pulsed immune reconstitution therapy, there are no data supporting its use as pulsed immune reconstitution therapy. Moreover, due to frequent severe adverse events, mitoxantrone is not recommended for routine use in patients with RRMS [40].

It is possible to become pregnant and breast-feed after the last administration of the drug in 4 months for alemtuzumab or in 6 months for cladribine.

Long-term remission is seen in most of patients after treatment with alemtuzumab and cladribine. After one full course of alemtuzumab 58.0-68.5\% of patients did not need additional cycles for 5 years. In the 5 -year extension of the CARE-MS I study $31.5 \%$ of the patients received additional alemtuzumab cycles: $22.1 \%$ received one additional cycle, $8.0 \%$ two additional cycles and $1.4 \%$ received three additional cycles [40].

After cladribine $3.5 \mathrm{mg} / \mathrm{kg}$ in the 2-year randomized placebo-controlled study, $75.1 \%$ of patients remained relapse-free in years 3 and 4 without further treatment. Primary interim analysis of CLASSIC-MS study which is the median 10 years' follow-up of patients from the cladribine tablets clinical development program showed that $73.5 \%$ of patients did not require further DMD treatment until $\geq 4$ years after last dose of cladribine tablets [41].

The main safety risks of pulsed immune reconstitution therapy include reactivation of latent infections such as tuberculosis, and risk of herpes zoster which is associated with severe lymphopenia. As a reflection of the mechanism of action of cladribine, lymphopenia was more frequent in the cladribine groups (combined cladribine group 27\% versus $1.8 \%$ in placebo) in the CLARITY trial. Overall, cladribine tablets were well tolerated and showed a favorable safety profile across all studies. For alemtuzumab several rare infections such as Listeria meningitis have been reported. The main disadvantage in alemtuzumab-treated patients is the risk of secondary immune-mediated disorders (including thyroid disease in $>40 \%$ of patients), which, however, has not been reported with cladribine. Also, unlike cladribine, long-term monitoring is required after the last administration of alemtuzumab. If pulsed immune reconstitution therapy has been decided, the choice between alemtuzumab and cladribine should be based on efficacy balanced against the risks [40].

\section{Conclusions}

Perceptions regarding pregnancy in women with MS and risks of DMD treatment are changing. Emerging data will continue to inform practical and evidence-based guidance for pregnancy planning in MS. Having MS should not in itself limit family planning.

The possibility of pregnancy should be considered when prescribing DMDs to all women of childbearing age. It is important to provide a framework to discuss concerns regarding pregnancy and MS and to consider uncertainty about long-term disease activity.

Treatment with DMDs should not be delayed. First-line injectable treatments, such as glatiramer acetate and beta interferon, may be continued during pregnancy. In patients with high disease activity pulsed immune reconstitution therapy can be considered before pregnancy, which is not recommended for 4 months following alemtuzumab and for 6 months following treatment with cladribine. After this time-frame there are no contraindications.

\section{References}

1. Walton C, King R, Rechtman L, et al. Rising prevalence of multiple sclerosis worldwide: Insights from the Atlas of MS, third edition. Mult Scler. 2020;26(14):1816-1821. doi: 10.1177/1352458520970841.

2. Hawkes $\mathrm{CH}$, Giovannoni G, Lechner-Scott J, Levy M. Is the incidence of multiple sclerosis really increasing? Mult Scler Relat Disord. 2020;45:102527. https://doi.org/10.1016/j.msard.2020.102527.

3. Sumelahti M-L, Holmberg M, Murtonen A, Huhtala H, Elovaara I. Increasing incidence in relapsing-remitting MS and high rates among young women in Finland: a thirty-year follow-up. Mult Scler Int. 2014;2014:186950. http://dx.doi.org/10.1155/2014/186950.

4. Coyle PK. Management of women with multiple sclerosis through pregnancy and after childbirth. Ther Adv Neurol Disord. 2016;9(3):198-210. doi: 10.1177/1756285616631897.

5. Kamm CP, Muehl S, Mircsof D, et al. Role of family planning in women with multiple sclerosis in Switzerland: results of the women with multiple sclerosis patient survey. Front Neurol. 2018;9:821. https://doi.org/10.3389/ fneur.2018.00821.

6. Dobson R, Dassan P, Roberts M, et al. UK consensus on pregnancy in multiple sclerosis: 'Association of British Neurologists' guidelines. Pract Neurol. 2019;19(2):106-114. doi: 10.1136/practneurol-2018-002060.

7. Amato MP, Bertolotto A, Brunelli R, et al. Management of pregnancy-related issues in multiple sclerosis patients: the need for an interdisciplinary approach. Neurol Sci. 2017;38(10):1849-58. doi: 10.1007/s10072-017-3081-8.

8. Hughes SE, Spelman S, Gray OM, et al. Predictors and dynamics of postpartum relapses in women with multiple sclerosis. Mult Scler. 2014;20(6):73946. doi: $10.1177 / 1352458513507816$.

9. Noseworthy JH, Lucchinetti C, Rodriguez M, Weinshenker BG. Multiple sclerosis. N Engl J Med. 2000;343(13):938-52. doi: 10.1056/ NEJM200009283431307.

10. Rasmussen PV, Magyari M, Yoon Moberg J, et al. Patient awareness about family planning represents a major knowledge gap in multiple sclerosis. Mult Scler Relat Disord. 2018;24:129-34. doi: 10.1016/j.msard.2018.06.006.

11. Hellwig K, Brzosko B, Airas L, Smith EK. Fertility and assisted reproductive techniques in women with MS. In: Houtchens MK, Sadovnick AD, editors. Health issues in women with multiple sclerosis. Wiwn: Springer; 2017. p. 9-17.

12. Confavreux C, Hutchinson M, Hours MM, et al. Rate of pregnancy-related relapse in multiple sclerosis. N Engl J Med. 1998;339(5):285-91. doi: 10.1056/NEJM199807303390501.

13. Vukusic S, Hutchinson M, Hours M, et al. Pregnancy and multiple sclerosis (the PRIMS study): clinical predictors of post-partum relapse. Brain. 2004;127(Pt 6):1353-60. doi: 10.1093/brain/awh152. 
14. Houtchens MK, Edwards NC, Schneider G, et al. Pregnancy rates and outcomes in women with and without MS in the United States. Neurology. 2018;91(17):e1559-69. doi: 10.1212/WNL.0000000000006384.

15. Hellwig K, Haghikia A, Rockhoff M, Gold R. Multiple sclerosis and pregnancy: experience from a nationwide database in Germany. Ther Adv Neur Disord. 2012;5(5):247-53. doi: 10.1177/1756285612453192.

16. Hellwig K. Pregnancy in multiple sclerosis. Eur Neurol. 2014;72(1):39-42. doi: $10.1159 / 000367640$.

17. Stuart M, Bergstrom L. Pregnancy and multiple sclerosis. J Midwifery Women's Health. 2011;56(1):41-7. doi: 10.1111/j.1542-2011.2010.00008.x.

18. Kaplan TB. Management of demyelinating disorders in pregnancy. Neurol Clin. 2019;37(1):17-30. doi: 10.1016/j.ncl.2018.09.007.

19. European Medicines Agency (EMA). Summary of Product Characteristics (SmPC): Lemtrada [Internet]. Amsterdam: EMA; (C) 1995-2021 [cited 2021 Jan 6]. Available from: https://www.ema.europa.eu/en/documents/ product-information/lemtrada-epar-product-information_en.pdf

20. European Medicines Agency (EMA). Summary of Product Characteristics (SmPC): Mavenclad [Internet]. Amsterdam: EMA; (C) 1995-2021 [cited 2021 Feb 16]. Available from: https://www.ema.europa.eu/en/documents/ product-information/mavenclad-epar-product-information_en.pdf

21. European Medicines Agency (EMA). Summary of Product Characteristics (SmPC): Tecfidera [Internet]. Amsterdam: EMA; ( ) 1995-2021 [cited 2020 Nov 16]. Available from: https://www.ema.europa.eu/en/documents/ product-information/tecfidera-epar-product-information_en.pdf

22. European Medicines Agency (EMA). Summary of Product Characteristics (SmPC): Copaxone 40 mg [Internet]. Amsterdam: EMA; (C) 1995-2021 [cited 2020 Sep 26]. Available from: https://mri.cts-mrp.eu/human/ downloads/DE_H_5283_004_FinalPI_2of2.pdf

23. European Medicines Agency (EMA). Summary of Product Characteristics (SmPC): Gilenya [Internet]. Amsterdam: EMA; (C) 1995-2021 [cited 2020 Dec 1]. Available from: https://www.ema.europa.eu/en/documents/ product-information/gilenya-epar-product-information_en.pdf

24. European Medicines Agency (EMA). Summary of Product Characteristics (SmPC): Rebif [Internet]. Amsterdam: EMA; @ 1995-2021 [cited 2020 Dec 1]. Available from: https://www.ema.europa.eu/en/documents/productinformation/rebif-epar-product-information_en.pdf

25. European Medicines Agency (EMA). Summary of Product Characteristics (SmPC): Betaferon [Internet]. Amsterdam: EMA; (C) 1995-2021 [cited 2020 Dec 1]. Available from: https://www.ema.europa.eu/en/documents/ product-information/betaferon-epar-product-information_en.pdf

26. European Medicines Agency (EMA). Summary of Product Characteristics (SmPC): Avonex [Internet]. Amsterdam: EMA; (C) 1995-2021 [cited 2020 Sep 12]. Available from: https://www.ema.europa.eu/en/documents/ product-information/avonex-epar-product-information_en.pdf

27. European Medicines Agency (EMA). Summary of Product Characteristics (SmPC): Novantrone and associated names [Internet]. Amsterdam: EMA; (C) 1995-2021 [cited 2020 Nov 2]. Available from: https://www. ema.europa.eu/en/documents/referral/novantrone-article-30-referralannex-iii_en.pdf
28. European Medicines Agency (EMA). Summary of Product Characteristics (SmPC): Tysabri [Internet]. Amsterdam: EMA; (C) 1995-2021 [cited 2021 Apr 12]. Available from: https://www.ema.europa.eu/en/documents/ product-information/tysabri-epar-product-information_en.pdf

29. European Medicines Agency (EMA). Summary of Product Characteristics (SmPC): Ocrevus [Internet]. Amsterdam: EMA; (C) 1995-2021 [cited 2021 Apr 12]. Available from: https://www.ema.europa.eu/en/documents/ product-information/ocrevus-epar-product-information_en.pdf

30. European Medicines Agency (EMA). Summary of Product Characteristics (SmPC): Aubagio [Internet]. Amsterdam: EMA; (C) 1995-2021 [cited 2021 Jan 22]. Available from: https://www.ema.europa.eu/en/documents/ product-information/aubagio-epar-product-information_en.pdf

31. Oh J, O'Connor P. An update of teriflunomide for treatment of multiple sclerosis. Ther Clin Risk Manag. 2013;9:177-90. doi: 10.2147/TCRM. S30947.

32. Rae-Grant A, Day GS, Marrie RA, et al. Practice guideline recommendations summary: Disease-modifying therapies for adults with multiple sclerosis: Report of the Guideline Development, Dissemination, and Implementation Subcommittee of the American Academy of Neurology. Neurology. 2018;90(17):777-88. doi: 10.1212/WNL.0000000000005347.

33. Montalban X, Gold R, Thompson AJ, et al. ECTRIMS/EAN Guideline on the pharmacological treatment of people with multiple sclerosis. Mult Scler. 2018;24(2):96-120. doi: 10.1177/1352458517751049.

34. Hellwig K, Geissbuehler Y, Sabidó M, et al. Pregnancy outcomes in interferon-beta-exposed patients with multiple sclerosis: results from the European Interferon-beta Pregnancy Registry. J Neurol. 2020;67(6):17151723. doi: 10.1007/s00415-020-09762-y.

35. Thiel S, Langer-Gould A, Rockhoff M, et al. Interferon-beta exposure during first trimester is safe in women with multiple sclerosis - A prospective cohort study from the German Multiple Sclerosis and Pregnancy Registry. Mult Scler. 2016;22(6):801-9. doi: 10.1177/1352458516634872.

36. Hellwig K, Geissbuehler Y, Sabidó M, et al. Pregnancy and infant outcomes with interferon beta: data from the European Interferon Beta Pregnancy Registry and Population Based Registries in Finland and Sweden. Mult Scler Relat Dis. 2018;26:P240. doi: 10.1016/j.msard.2018.10.036.

37. Sandberg-Wollheim M, Alteri E, Moraga MS, Kornmann G. Pregnancy outcomes in multiple sclerosis following subcutaneous interferon beta-1a therapy. Mult Scler. 2011;17(4):423-30. doi: 10.1177/1352458510394610.

38. Hale TW, Siddiqui AA, Baker TE. Transfer of interferon $\beta$-1a into human breastmilk. Breastfeed Med. 2012;7(2):123-5. doi: 10.1089/bfm.2011.0044.

39. Almas S, Vance J, Baker T, Hale T. Management of multiple sclerosis in the breastfeeding mother. Mult Scler Int. 2016;2016:6527458. doi: $10.1155 / 2016 / 6527458$.

40. Sorensen PS, Sellebjerg F. Pulsed immune reconstitution therapy in multiple sclerosis. Ther Adv Neurol Disord. 2019;12:1-16. doi: 10.1177/1756286419836913.

41. Giovannoni G, Leist T, Aydemir A, Verdun Di Cantogno E. CLASSICMS: Long-term efficacy and real-world treatment patterns for patients receiving Cladribine tablets - Interim data with 8-14 years follow-up. In: MSVirtual2020: 8th Joint ACTRIMS-ECTRIMS Meeting; 2020 Sep 25-26; Washington.

\section{Authors' ORCID iDs and academic degrees}

Anna Belenciuc, MD, PhD Applicant - https://orcid.org/0000-0002-0904-1410

Ana-Maria Bubuioc, MD - https://orcid.org/0000-0002-3774-6063

Olesea Odainic, MD, PhD - https://orcid.org/0000-0003-0225-1009

Marina Sangheli, MD, PhD, Associate Professor of Neurology - https:/orcid.org/0000-0003-4064-9472

Mihail Gavriliuc MD, PhD, Professor of Neurology - https://orcid.org/0000-0002-5789-2842

Vitalie Lisnic, MD, PhD, Professor of Neurology - https://orcid.org/0000-0002-5432-8859

\section{Authors' contribution}

$\mathrm{AB}$ conducted literature review, wrote the manuscript, revised the final text; AMB conducted literature review; OO wrote the manuscript; MS wrote the manuscript; MG revised the final text; VL conducted literature review, wrote the manuscript, revised the final text. All the authors approved the final version of the manuscript.

Funding. This study was supported by Nicolae Testemitanu State University of Medicine and Pharmacy. The review study was the authors' initiative. The authors are independent and take responsibility for the integrity of the data and accuracy of the data analysis.

Ethics approval and consent to participate. No approval was required for this study.

Conflict of interests. No competing interests were disclosed. 